\title{
Prednisolone suppression test in depression: prospective study of the role of HPA axis dysfunction in treatment resistance
}

\author{
Mario F. Juruena, Carmine M. Pariante, Andrew S. Papadopoulos, Lucia Poon, Stafford Lightman \\ and Anthony J. Cleare
}

\section{Background}

People with severe depressive illness have raised levels of cortisol and reduced glucocorticoid receptor function.

\begin{abstract}
Aims
To obtain a physiological assessment of hypothalamicpituitary-adrenal (HPA) axis feedback status in an in-patient sample with depression and to relate this to prospectively determined severe treatment resistance.
\end{abstract}

\section{Method}

The prednisolone suppression test was administered to 45 in-patients with depression assessed as resistant to two or more antidepressants and to 46 controls, prior to intensive multimodal in-patient treatment.

\section{Results}

The patient group had higher cortisol levels than controls, although the percentage suppression of cortisol output after prednisolone in comparison with placebo did not differ. Nonresponse to in-patient treatment was predicted by a more dysfunctional HPA axis (higher cortisol levels postprednisolone and lower percentage suppression).

\section{Conclusions}

In patients with severe depression, HPA axis activity is reset at a higher level, although feedback remains intact. However, prospectively determined severe treatment resistance is associated with an impaired feedback response to combined glucocorticoid and mineralocorticoid receptor activation by prednisolone.

\section{Declaration of interest}

None.
A substantial proportion of patients with depression respond poorly to treatment; this group accounts for about half the total treatment costs for this disorder. ${ }^{1}$ Few data are available as to any specific biological substrate for this treatment resistance. One of the most consistent findings in depression is hypothalamic-pituitary-adrenal (HPA) axis dysfunction; ${ }^{2}$ furthermore, glucocorticoid receptor resistance is particularly evident in patients with treatment-resistant depression. ${ }^{3,4}$ It is not known whether HPA axis dysfunction contributes to treatment resistance, although persistent glucocorticoid receptor resistance in depression is associated with relapse. ${ }^{5,6}$ A suppressive test of the HPA axis using prednisolone has now been developed; 7 this differs from the traditional dexamethasone suppression test in that whereas dexamethasone probes the function of glucocorticoid receptors only, the prednisolone suppression test (PST) probes both glucocorticoid and mineralocorticoid receptors. Since endogenous HPA axis feedback involves both glucocorticoid and mineralocorticoid receptors, and since there is some evidence that mineralocorticoid receptors can compensate for altered glucocorticoid receptor function, ${ }^{8}$ prednisolone should provide a more valid test of the HPA axis in depression. ${ }^{9}$ In a preliminary study of 18 participants with depression, we found a normal suppressive response to prednisolone $(5 \mathrm{mg})$ even though the same individuals demonstrated non-suppression to dexamethasone. In this paper we report the results of administering the PST to an extended cohort of 45 people receiving in-patient treatment for depression. Our aim was to understand more about the role of the HPA axis in severe depression, and specifically in the aetiology of treatment resistance, using the PST as a tool. Our hypothesis was that HPA axis impairment as elicited by the PST would be associated with more severe illness clinically and a higher level of treatment resistance. The finding of a link between the
HPA axis and treatment resistance could also suggest new therapeutic targets in patients not responsive to current treatments.

\section{Method}

\section{Study design}

The study used a single-blind non-randomised placebo-controlled repeated-measures design, as previously used for the validation of the PST in healthy controls and patients with depression. ${ }^{7,9}$ On day 1 , participants received placebo capsules and on day 2, they received prednisolone capsules $(5 \mathrm{mg})$, both at $22.00 \mathrm{~h}$. No alcohol, coffee, tea or meals were allowed after each capsule. On the day following each capsule administration, saliva samples were collected at $09.00 \mathrm{~h}, 12.00 \mathrm{~h}$ and $17.00 \mathrm{~h}$. Participants with depression underwent a full clinical assessment at baseline and after the completion of a period of intensive, multimodal in-patient treatment on the National Affective Disorders Unit as described below.

\section{Participants}

Two groups were recruited: a group of 45 individuals with major depression who were in-patients on the National Affective Disorders Unit of the Bethlem Royal Hospital, South London and Maudsley National Health Service (NHS) Trust, and a healthy control group $(n=46)$ recruited from our database of controls from hospital staff, students and the local community. Patients and controls were matched according to age (to within a limit of 5 years), gender and body mass index (to within a range of $5 \mathrm{~kg} / \mathrm{m}^{2}$ ). Patients were included in this study if they were aged 18-75 years and diagnosed as having major depressive disorder according to DSM-IV criteria. ${ }^{10}$ In addition, all patients had a 
disorder that was moderately treatment-resistant on the basis of prior non-response to at least two different classes of antidepressants. A thorough medical examination was performed to assess comorbidity, physical disorders, general medical conditions, lifestyle, psychosocial problems and stress. For practical reasons it was not possible to test most patients in a drug-free state; for those continuing to take medication, a switch in regimen was avoided for at least 7 days before the experimental procedures.

Exclusion criteria for the patient group were a history of hypersensitivity to corticosteroids or steroid use, heavy smoking (more than 25 cigarettes a day), a viral illness during the preceding 2 weeks, pregnancy or lactation, alcohol dependence and significant physical illness (severe allergy, autoimmune disease, hypertension, malignancy, or haematological, endocrine, pulmonary, renal, hepatic, gastrointestinal or neurological disease). Patients with bipolar affective disorder, psychotic symptoms unrelated to their depressive disorder or an organic cause for their depression were excluded.

The control group participants were physically healthy on the basis of a complete medical history and examination, were not taking any psychotropic medication, were not taking any hormonal medication (including oral contraceptives) and had no history of hypersensitivity to corticosteroids. Urine tests for illicit drug use and pregnancy were conducted before the start of the study. Healthy individuals were excluded if they had a personal history or first-degree relative history of a DSM-IV Axis I disorder. The Beck Depression Inventory II (BDI-II) and the 21-item Hamilton Rating Scale for Depression (HRSD) provided information on the severity of control participants' depressive symptoms. ${ }^{11,12}$ Inclusion in the control group required a BDI-II score of less than 9 (in fact, none of the group scored above 6).

The study protocols were all approved by the research ethical committee of the Institute of Psychiatry and South London and Maudsley NHS Trust. Written informed consent was obtained from all participants.

\section{Clinical assessment of the patient sample}

The Affective Disorders Unit receives referrals of many patients with long-standing or difficult to treat depressive illness, usually with a history of not responding to pharmacotherapy or psychotherapy. Patients underwent detailed assessment using the tools described below in order to clarify the main features of their illness. Many of these measures are already part of the unit's normal assessment process, but some were added for this research protocol. For diagnostic assessment we used the Structured Clinical Interview for DSM-IV Axis I disorders (SCID-I) and the Structured Clinical Interview for DSM-III-R Personality Disorders (SCID-II). ${ }^{13,14}$

\section{Treatment resistance}

For assessment of treatment resistance we used the Antidepressant Treatment History Form to assess the number of prior treatments of adequate dosage and duration to which the patient had adhered. ${ }^{15}$ According to Sackeim, resistance to a given treatment could also be concluded if, despite continued adherence to the same medication and dosage that produced an initial response, a patient experienced relapse or recurrence of a depressive episode. ${ }^{15}$ We also used Thase \& Rush's staging criteria, which recognise five stages of treatment resistance according to the number of treatment trials adequately delivered. ${ }^{16}$

\section{Clinical severity}

For clinical severity of depression we used the 21-item HRSD, the Montgomery-Åsberg Depression Rating Scale (MADRS), the
Inventory of Depressive Symptomatology (IDS) self-report version, the BDI-II and the Beck Anxiety Inventory (BAI). ${ }^{17-19}$

\section{Other measures}

The following measures were also used:

(a) for suicide assessment we used the Beck Scale for Suicide Ideation (BSI) and the Beck Hopelessness Scale; ${ }^{20,21}$

(b) for cognitive function we used the Mini-Mental State Examination (MMSE); ${ }^{22}$

(c) for functional capacity and disability we used the Social Adaptation Self-evaluation Scale (SASS), the GolombokRust Inventory of Marital State (GRIMS) and the Dysfunctional Attitudes Scale (DAS); ${ }^{23-25}$

(d) for sleep disturbance we used the Pittsburgh Sleep Quality Index (PSQI); ${ }^{26}$

(e) for environmental stress we used the Recent Life Changes Questionnaire (RLCQ), the Childhood Experience of Care and Abuse (CECA) interview and the Childhood Experience of Care and Abuse Questionnaire (CECA-Q) ${ }^{27-29}$

\section{In-patient treatment protocol}

All patients underwent intensive in-patient treatment for their depression for a mean of 20 weeks. Treatment consisted of an individualised combination of the following therapies as clinically indicated for each patient: intensive psychopharmacology, using combinations of medications as indicated by the Maudsley prescribing guidelines; ${ }^{30}$ weekly cognitive-behavioural therapy; daily occupational therapy; fortnightly couple and sexual therapy; alleviation of any physical health consequences or corollaries of depression (such as hypercholesterolaemia, hypertension, obesity, malnutrition and dental problems); and supportive and enabling nursing care including group sessions for anxiety management and behavioural activation. The patients' response to treatment was carefully assessed by repeating shortly before discharge the same psychometric measures that were administered at baseline. Responders and non-responders to treatment were defined using the a priori definition of a reduction in HRSD score of $50 \%$ or greater.

\section{Endocrine protocol}

The prednisolone suppression test was administered shortly after admission for patients (range 5-21 days). Both patients and controls were admitted to the research rooms of the Affective Disorders Unit, where they spent the period from $08.45 \mathrm{~h}$ to $17.15 \mathrm{~h}$ engaged in sedentary activities. Snacks, meals and drinks were standardised throughout the day. Saliva samples were collected using untreated cotton swabs (Salivettes, Sarstedt, Leicester, UK). Participants were asked to place the swab in their mouth and move it around with their tongue until it was saturated with saliva; the swab was then replaced in the vial without being touched. Saliva was separated from the cotton roll by quick centrifugation ( $3500 \mathrm{rev} / \mathrm{min}$ for $10 \mathrm{~min}$ ) and samples were stored in a freezer at $-40{ }^{\circ} \mathrm{C}$ until assayed. Samples were always collected at the same time of day to control for circadian variations. In addition to saliva samples, blood samples were taken by venepuncture at $09.00 \mathrm{~h}$ on the day after administration of prednisolone and placebo in order to measure plasma prednisolone levels. The saliva samples were always collected before blood sampling or meals to avoid confounding effects of blood collection or eating. 


\section{Saliva cortisol assay}

Salivary cortisol level was measured using a time-resolved immunofluorescent assay as previously described. ${ }^{7,9}$ The intraassay precision was $8.8 \%$ at $0.3 \mathrm{nmol} / \mathrm{l}, 8.9 \%$ at $1.0 \mathrm{nmol} / \mathrm{l}$ and $6.6 \%$ at $4.6 \mathrm{nmol} / \mathrm{l}$. The inter-assay precision was $7.7 \%$ at $2.1 \mathrm{nmol} / \mathrm{l}$ and $5.9 \%$ at $9.2 \mathrm{nmol} / \mathrm{l}$. The minimal detection concentration was $0.1 \mathrm{nmol} / \mathrm{l}$ and there was no 'drifting' evident in assays up to 200 wells. The cross-reactivity of the antiserum was prednisolone 28\%, 11-deoxycortisol $10 \%$, cortisone $1 \%$ and corticosterone $1 \%$.

\section{Plasma prednisolone assays}

Plasma levels of prednisolone were measured by high-performance liquid chromatography (Hewlett-Packard UV Detector linked to a ChemStation collection system; Agilent Technologies, www.chem.agilent.com). The calibration graph of the method was in the range $5-500 \mathrm{ng} / \mathrm{ml}$. The intra-assay precision for prednisolone was $11.2 \%$ at $5 \mathrm{ng} / \mathrm{ml}, 5.2 \%$ at $18 \mathrm{ng} / \mathrm{ml}$ and $2.0 \%$ at $225 \mathrm{ng} / \mathrm{ml}$. The inter-assay precision was $10.7 \%$ at $5 \mathrm{ng} / \mathrm{ml}, 9.6 \%$ at $18 \mathrm{ng} / \mathrm{ml}$ and $3.1 \%$ at $225 \mathrm{ng} / \mathrm{ml}$.

\section{Statistical analysis}

The general linear model analysis for repeated measures was used to examine both between-group differences (patients $v$. controls) and within-group differences (placebo $v$. prednisolone) in salivary cortisol levels for all time points. We also used as summary measures the total salivary cortisol output, calculated as the area under the curve (AUC) using the trapezoidal method, after placebo $\left(\mathrm{AUC}_{\mathrm{PLACEBO}}\right)$ and prednisolone $\left(\mathrm{AUC}_{\mathrm{PRED}}\right)$, and further calculated the percentage suppression of salivary cortisol for each individual. The percentage suppression represented the $\mathrm{AUC}_{\mathrm{PRED}}$

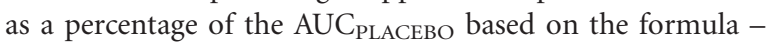

$$
\text { Percentage suppression }=\left(\frac{\mathrm{AUC}_{\mathrm{PLACEBO}}-\mathrm{AUC} \mathrm{C}_{\mathrm{PRED}}}{\mathrm{AUC}_{\mathrm{PLACEBO}}}\right) \times 100
$$

We used $t$-tests to compare the AUC values, percentage suppression, clinical data and prednisolone plasma levels. Correlations between the AUC values and psychometric measures were examined using Pearson's product-moment correlation coefficients. Chi-squared tests were used to analyse categorical variables. The relationship between endocrine status and subsequent treatment response was tested by comparing the AUC values between treatment responders and non-responders using an independent $t$-test. All analyses were conducted using the Statistical Package for the Social Sciences, SPSS for Windows, release 13.0. All values are presented as means and standard error of the mean. All probability values reported are two-tailed. A value of $P<0.05$ was considered statistically significant.

\section{Results}

\section{Clinical assessment}

At baseline, patients had a mean BDI-II score of 38 (s.e.m.=1.3) and a mean HRSD score of 23.4 (s.e.m.=0.9). As expected, the mean scores on these scales were lower in the control group (BDI-II mean score 1.9 , s.e.m. $=0.2, \quad t=-26.13$, d.f. $=1,89$, $P<0.001$; HRSD mean score 4.1 , s.e.m. $=0.3, t=-19.31$, d.f. $=1,89$, $P<0.001$ ). There was a wide range of Axis I comorbidity (Table 1). According to the SCID-II, almost half $(22 / 45 ; 49 \%)$ of the patient group had some degree of comorbidity in Axis II. It is also noteworthy that more than two-thirds of the patient group (31/45; $69 \%$ ) had experienced some form of early life stress according to the CECA-Q: specifically, $25(55 \%)$ had experienced parental neglect or emotional abuse, 10 (22\%) had experienced physical abuse and 9 (20\%) had experienced sexual abuse. Among the 45 patients, 38 were taking medication at the time of testing (Table 1). Seven $(16 \%)$ were drug-free for at least 14 days before testing.

Using the a priori definition of treatment response, 24 of 45 patients showed a response to treatment (and were designated 'responders') and 21 did not (designated 'non-responders'). Among the responders, all the scales measuring severity of depression or related symptoms showed significant improvement between admission and discharge (Table 2). The non-responders group showed no significant improvement on any of the scales, although there was a trend towards improvement in HRSD,

\begin{tabular}{|c|c|c|}
\hline & $\begin{array}{l}\text { Depression } \\
\text { group } \\
(n=45)\end{array}$ & $\begin{array}{l}\text { Control } \\
\text { group } \\
(n=46)\end{array}$ \\
\hline Female gender, $n(\%)$ & $37(82)$ & $29(63)$ \\
\hline Age, years: mean (s.e.m.) & $50.9(1.5)$ & $46.5(2.1)$ \\
\hline BMl, kg/m²: mean (s.e.m.) & $29.7(0.9)$ & $26.9(0.7)$ \\
\hline Years of education: mean (s.e.m.) & $12.4(0.4)$ & $12.8(0.6)$ \\
\hline $\begin{array}{l}\text { SCID-I primary diagnosis of major } \\
\text { depressive disorder, } n(\%)\end{array}$ & $45(100)$ & $0(0)$ \\
\hline $\begin{array}{l}\text { Comorbidity, } n \text { (\%) } \\
\text { Generalised anxiety disorder } \\
\text { Atypical depression } \\
\text { Social phobia } \\
\text { PTSD } \\
\text { Eating disorder } \\
\text { Sleep disorder } \\
\text { Dysthymia } \\
\text { Panic disorder and agoraphobia } \\
\text { Somatisation disorder }\end{array}$ & $\begin{array}{c}15(33) \\
5(11) \\
5(11) \\
5(11) \\
4(8) \\
4(8) \\
4(8) \\
2(4) \\
2(4)\end{array}$ & \\
\hline $\begin{array}{l}\text { Age at onset, years: mean (s.e.m.) } \\
\text { First MDE } \\
\text { Current episode }\end{array}$ & $\begin{array}{l}29.3(1.6) \\
50.9(1.5)\end{array}$ & \\
\hline No. of prior MDE: mean (s.e.m.) & $7.9(0.7)$ & \\
\hline $\begin{array}{l}\text { Duration of current MDE, months: } \\
\text { mean (s.e.m.) }\end{array}$ & $38.4(4.5)$ & \\
\hline Duration of illness, years: mean (s.e.m.) & $20.2(2.0)$ & \\
\hline $\begin{array}{l}\text { No. of previous hospital admissions: } \\
\text { mean (s.e.m.) }\end{array}$ & $3.9(0.6)$ & \\
\hline $\begin{array}{l}\text { No. of prior adequate treatment trials: } \\
\text { mean (s.e.m.) }\end{array}$ & $12.8(1.2)$ & \\
\hline $\begin{array}{l}\text { Duration of current admission, weeks: } \\
\text { mean (s.e.m.) }\end{array}$ & $20.3(2.2)$ & \\
\hline \multicolumn{3}{|l|}{ Current medication, $n(\%)$} \\
\hline Mood stabiliser & $35(78)$ & $0(0)$ \\
\hline SSRI/SNRI & $35(78)$ & $0(0)$ \\
\hline Benzodiazepine & $19(42)$ & $0(0)$ \\
\hline Atypical antipsychotic & $16(36)$ & $0(0)$ \\
\hline Tricyclic antidepressant & $11(24)$ & $0(0)$ \\
\hline MAOI & $11(24)$ & $0(0)$ \\
\hline Drug free & $7(16)$ & $46(100)$ \\
\hline Other antipsychotics & $3(7)$ & $0(0)$ \\
\hline ECT in the past, $n(\%)$ & $23(51)$ & $0(0)$ \\
\hline \multicolumn{3}{|l|}{ Treatment resistance stage ${ }^{a} n(\%)$} \\
\hline Stage 5 & $34(76)$ & \\
\hline Stage 4 & $9(20)$ & \\
\hline Stage 3 & $2(4)$ & \\
\hline \multicolumn{3}{|c|}{$\begin{array}{l}\text { BMI, body mass index; ECT, electroconvulsive therapy; MAOI, monamine oxidase } \\
\text { inhibitor; MDE, major depressive episode; PTSD, post-traumatic stress disorder; } \\
\text { SCID-I, Structured Clinical Interview for DSM-IV Axis I disorders; SSRI, selective } \\
\text { serotonin reuptake inhibitor; SNRI, serotonin and noradrenaline reuptake inhibitor. } \\
\text { a. Categorised according to Thase \& Rush treatment resistance criteria. }{ }^{16}\end{array}$} \\
\hline
\end{tabular}


Table 2 Psychometric scores on admission and discharge in the patient sample

\begin{tabular}{|c|c|c|c|}
\hline & $\begin{array}{l}\text { All patients } \\
\quad(n=45) \\
\text { Mean (s.e.m.) }\end{array}$ & $\begin{array}{c}\text { Non-responders } \\
\quad(n=21) \\
\text { Mean (s.e.m.) }\end{array}$ & $\begin{array}{l}\text { Responders }^{\mathrm{a}} \\
\quad(n=24) \\
\text { Mean (s.e.m.) }\end{array}$ \\
\hline HRSD admission & $23.4(0.9)$ & $21.5(1.3)$ & $25.0(1.2)$ \\
\hline HRSD discharge & $14.5(1.1)$ & $19.8(1.3)$ & $9.8(0.9)$ \\
\hline$P$ & $<0.001$ & 0.074 & $<0.001$ \\
\hline BDI-II admission & $38.0(1.4)$ & $39.3(1.9)$ & $36.8(1.9)$ \\
\hline BDI-II discharge & $30.9(1.9)$ & $33.1(2.5)$ & $28.8(3.1)$ \\
\hline$P$ & 0.004 & 0.064 & 0.028 \\
\hline MADRS admission & $35.2(1.8)$ & $34.8(2.3)$ & $35.8(3.2)$ \\
\hline MADRS discharge & $27.9(3.6)$ & $33.0(4.2)$ & $21.8(5.3)$ \\
\hline$P$ & 0.05 & 0.682 & 0.033 \\
\hline IDS-SR admission & $49.8(2.5)$ & $50.8(3.4)$ & $48.9(3.6)$ \\
\hline IDS-SR discharge & $36.2(5.8)$ & $40.7(8.7)$ & $31.0(7.8)$ \\
\hline$P$ & 0.017 & 0.315 & 0.033 \\
\hline BHS admission & $16.7(0.7)$ & $15.9(1.2)$ & $17.4(0.7)$ \\
\hline BHS discharge & $13.7(1.4)$ & $13.7(1.5)$ & $13.7(3.5)$ \\
\hline$P$ & 0.044 & 0.278 & 0.105 \\
\hline BSI admission & $22.7(1.4)$ & $24.0(2.0)$ & $21.5(1.9)$ \\
\hline BSI discharge & $13.6(1.7)$ & $16.0(2.2)$ & $11.1(2.3)$ \\
\hline$P$ & $<0.001$ & 0.063 & 0.003 \\
\hline BAl admission & $25.1(2.1)$ & $23.7(2.8)$ & $26.4(3.0)$ \\
\hline BAl discharge & $23.6(3.6)$ & $27.3(2.3)$ & $18.4(7.9)$ \\
\hline$P$ & 0.718 & 0.339 & 0.267 \\
\hline DAS admission & $104.6(5.6)$ & $104.4(8.7)$ & $104.7(7.5)$ \\
\hline DAS discharge & $109.4(14.8)$ & $112.0(21.3)$ & $105.0(22.7)$ \\
\hline$P$ & 0.709 & 0.694 & 0.989 \\
\hline MMSE admission & $28.1(0.4)$ & $28.5(0.6)$ & $27.6(0.7)$ \\
\hline MMSE discharge & $27.8(0.5)$ & $28.3(0.7)$ & $27.3(0.8)$ \\
\hline P & 0.744 & 0.837 & 0.777 \\
\hline PSQI admission & $12.1(0.7)$ & $12.0(1.1)$ & $12.1(0.8)$ \\
\hline PSQI discharge & $10.9(1.1)$ & $11.1(1.2)$ & $10.5(2.3)$ \\
\hline$P$ & 0.338 & 0.603 & 0.418 \\
\hline SASS admission & $31.4(4.0)$ & $37.2(7.1)$ & $29.0(4.8)$ \\
\hline SASS discharge & $33.5(1.9)$ & $35.0(2.3)$ & $31.7(3.1)$ \\
\hline$P$ & 0.638 & 0.779 & 0.698 \\
\hline RLCQ admission & $321.5(29.4)$ & $354.4(42.8)$ & 279.5 (37.1) \\
\hline GRIMS admission & $31.5(4.0)$ & $25.6(4.9)$ & $36.6(5.7)$ \\
\hline \multicolumn{4}{|c|}{$\begin{array}{l}\text { BAI, Beck Anxiety Inventory; BDI-II, Beck Depression Inventory-ll; BHS, Beck } \\
\text { Hopelessness Scale; BSI, Beck Scale for Suicidal Ideation; DAS, Dysfunctional Attitudes } \\
\text { Scale; ;RIMS, Golombok-Rust Inventory of Marital State; HRSD, Hamilton Rating Scale } \\
\text { for Depression; IDS-SR, Inventory of Depressive Symptomatology - Self Rated; MADRS } \\
\text { Montgomery-Assberg Depression Rating Scale; MMSE, Mini-Mental State Examination; } \\
\text { PSQI, Pittsburgh Sleep Quality Index; RLCQ, Recent Life Change Questionnaire; } \\
\text { SASS, Social Adaptation Self-evaluation Scale. } \\
\text { a. Response defined as a reduction in HRSD score of } 50 \% \text { or more. }\end{array}$} \\
\hline
\end{tabular}

BDI-II and BSI scores (Table 2). There was no significant difference in clinical features between the responder and nonresponder groups. Both groups of patients followed the same treatment guidelines and there was no significant difference between them in the composition of treatments administered during the admission.

\section{Endocrine assessment}

In the between-participants analyses, the patient group had higher salivary cortisol levels compared with controls, both after placebo and after prednisolone (Fig. 1). The following main factors were entered into a general linear model: challenge (placebo $v$. prednisolone), group (patients $v$. controls) and time $(09.00 \mathrm{~h}, 12.00 \mathrm{~h}$ and $17.00 \mathrm{~h}$ ). According to the general linear modeal analysis there was a significant difference between groups $(F=26.19$, d.f. $=1,267$, $P<0.001$; i.e. overall higher cortisol levels in patients), a between-challenge effect $(F=335.19$, d.f. $=1,267, P<0.001$; i.e. overall higher cortisol levels after placebo than prednisolone), an

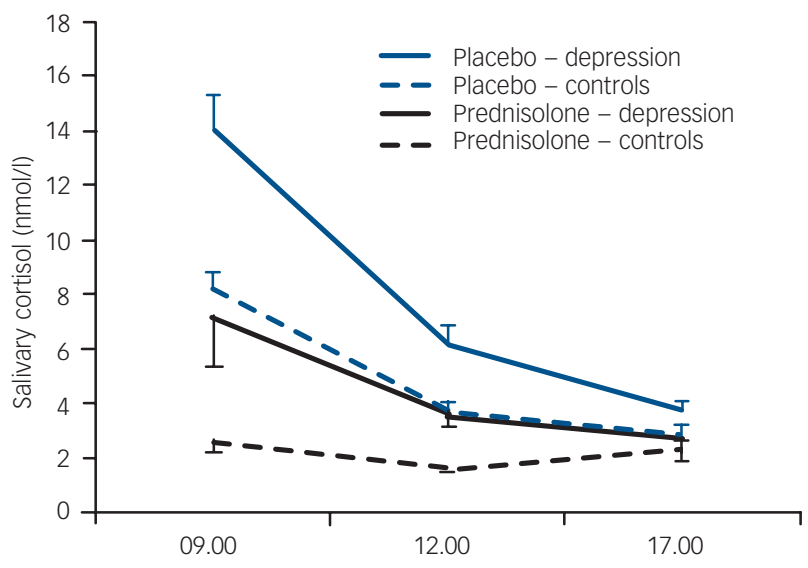

Fig. 1 Salivary cortisol levels ( $\mathrm{nmol} / \mathrm{l})$ in healthy controls $(n=46)$ and in-patients with depression $(n=45)$ at $09.00 \mathrm{~h}, 12.00 \mathrm{~h}$ and $17.00 \mathrm{~h}$, after the administration at $22.00 \mathrm{~h}$ the previous night of placebo or $5 \mathrm{mg}$ prednisolone.

effect of time $(F=34.63$, d.f. $=2,267, P<0.001$; i.e. overall higher cortisol concentration in the morning than in the afternoon) and a group $\times$ time interaction $(F=6.00$, d.f. $=2,267, P=0.003$; i.e. the fall in cortisol levels over time was larger in the patient group owing to the higher $09.00 \mathrm{~h}$ values). There was also a challenge $x$ time interaction $(F=17.6$, d.f. $=2,267, \quad P<0.001$; i.e. greater suppression by prednisolone in the morning than the afternoon, due to the higher absolute values in the morning).

Subsequent pairwise analyses within groups were conducted separately in patients and controls. In controls there was a main effect of challenge (placebo $v$. prednisolone, $F=76.8$, d.f. $=1,135$, $P<0.001)$ and a challenge $\times$ time interaction $(F=24.3$, d.f. $=1,135, P<0.001)$. In patients there were also a main effect of challenge (placebo $v$. prednisolone, $F=23.06$, d.f. $=1,132$, $P<0.001)$ and a challenge $\times$ time interaction $(F=5.96$; d.f. $=2,132, P=0.003)$.

The results of the general linear model analysis were confirmed by the analysis of the total cortisol output, measured using the AUC. Patients had larger mean AUC cortisol compared with controls both after placebo (AUC 1.6 times higher) and after prednisolone (AUC $\mathrm{PRED}_{\mathrm{PR}}$ was approximately twice as high) (Table 3 ). Patients and controls showed similar percentage suppression by prednisolone (Table 3 ).

In summary, these results showed that in-patients with depression and a history of moderate prior treatment resistance have marked hypercortisolism both before and after administration of prednisolone, but a similar percentage suppression of salivary cortisol to healthy controls.

\section{Prediction of treatment response using the PST}

The cortisol profiles after placebo and the prednisolone suppression test are shown in Fig. 2, divided into those who went on to respond to treatment and those who did not. There was a significant difference in the $\mathrm{AUC}_{\mathrm{PRED}}$ between those who subsequently responded to treatment and those who did not: responders $23.5 \mathrm{nmol} / \mathrm{l}$ per hour (s.e.m.=4.2) $v$. non-responders $41.9 \mathrm{nmol} / 1$ per hour (s.e.m. $=7.7$ ); $t=2.1$, d.f. $=43, P=0.046$. On the other hand, the comparison of $\mathrm{AUC}_{\mathrm{PLACEBO}}$ did not show a significant difference between these patient subgroups: responders $53.1 \mathrm{nmol} / \mathrm{l}$ per hour $($ s.e.m.=8.2) v. non-responders $57.2 \mathrm{nmol} / \mathrm{l}$ per hour (s.e.m.=5.7); $t=0.4$, d.f. $=43, P=0.694$ (Table 3, Fig. 3). 


\begin{tabular}{|c|c|c|c|c|}
\hline & $\begin{array}{c}\text { AUC } \text { PLACEBo } \\
\text { Mean (s.e.m.) }\end{array}$ & $\begin{array}{c}\text { AUC } \text { PRED } \\
\text { Mean (s.e.m.) }\end{array}$ & $\begin{array}{c}\text { Suppression, }{ }^{a} \% \\
\text { Mean (s.e.m.) }\end{array}$ & $\begin{array}{c}\text { Plasma prednisolone } \\
\text { levels, ng/ml } \\
\text { Mean (s.e.m.) }\end{array}$ \\
\hline \multicolumn{5}{|l|}{ Group } \\
\hline Controls $(n=46)$ & $33.8(2.5)$ & $16.1(1.6)$ & $-49.6(4.0)$ & $66.5(10.9)$ \\
\hline Depression $(n=45)$ & $55.1(5.1)$ & $32.1(4.4)$ & $-42.2(4.8)$ & $56.1(5.1)$ \\
\hline$P$ & $<0.001$ & $<0.001$ & 0.24 & 0.40 \\
\hline \multicolumn{5}{|l|}{ Patients with depression } \\
\hline Responding to subsequent treatment $(n=24)$ & $53.1(8.2)$ & $23.5(4.2)$ & $-52.5(4.7)$ & 74.9 (17.3) \\
\hline Not responding to subsequent treatment $(n=21)$ & $57.2(5.7)$ & $41.9(7.7)$ & $-30.6(8.2)$ & $54.8(10.1)$ \\
\hline$P$ & 0.69 & 0.046 & 0.022 & 0.34 \\
\hline
\end{tabular}

Furthermore, comparing the percentage suppression of cortisol output after prednisolone, there was a significant difference between subsequent treatment responders and non-responders: responders $-52.5 \% \quad$ (s.e.m. $=4.7) \quad v$. non-responders $-30.6 \%$ (s.e.m.=8.2); $t=2.4$, d.f. $=43, P=0.022$ (Table 3). Indeed, as can be

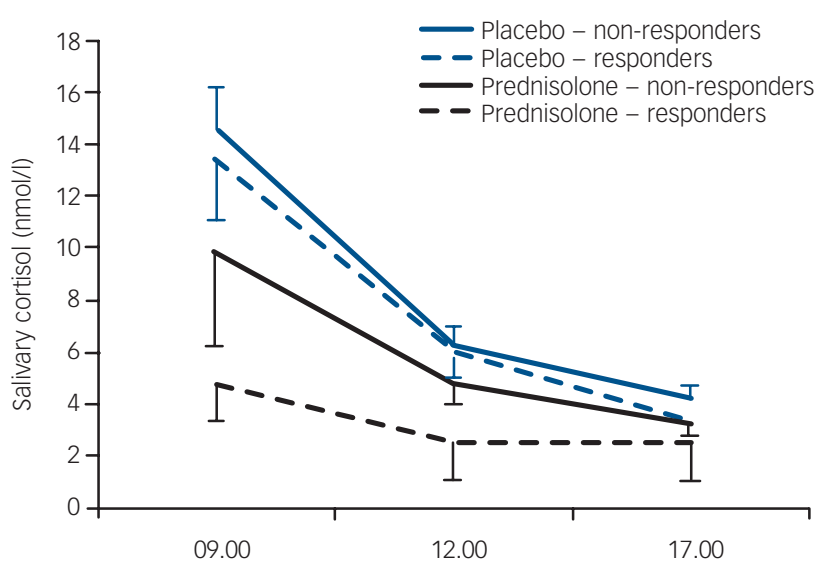

Fig. 2 Salivary cortisol levels $(\mathrm{nmol} / \mathrm{l})$ in 45 in-patients with depression at $09.00 \mathrm{~h}, 12.00 \mathrm{~h}$ and $17.00 \mathrm{~h}$, after the administration at $22.00 \mathrm{~h}$ the previous night of placebo or $5 \mathrm{mg}$ prednisolone. Patients are divided into those who subsequently responded to treatment and those who did not.

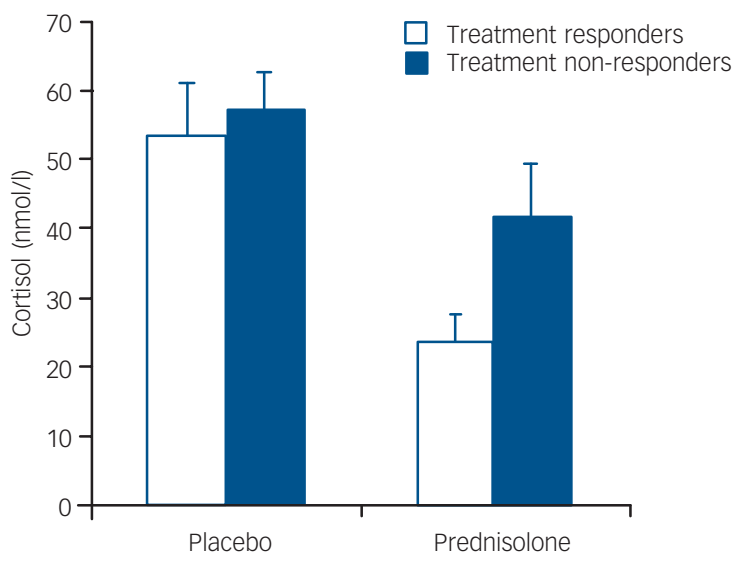

Fig. 3 Cortisol output (measured as area under the curve) after placebo and $5 \mathrm{mg}$ prednisolone in in-patients with depression divided into those who subsequently responded to treatment $(n=24)$ and those who did not $(n=21)$. seen in Table 3 and Fig. 4, responders had a percentage suppression $(-52.5 \%)$ virtually identical to that of healthy controls $(-49.6 \%$; $t=-0.44$, d.f. $=68, P=0.66)$, whereas that of non-responders was lower than that of healthy controls $(-30.6 \% ; t=2.3$, d.f. $=65, P=0.02)$.

These findings indicate that the results of the PST - both absolute salivary cortisol values after prednisolone and the percentage suppression after prednisolone compared with placebo - on admission to the in-patient unit differed between those who went on to respond to treatment and those who did not (Fig. 3).

\section{Relationship between PST and psychometric measures}

We correlated the AUC values and psychometric measures in the patient group. Given the number of psychometric measures taken, we corrected for multiple comparisons using the rough false discovery rate - i.e. the $\alpha$-value was adjusted by $(n+1) / 2 n$, which for 13 tests gives an adjusted significance level of $P<0.027$. There was a significant negative correlation between the AUC $C_{P R E D}$ and the Beck Hopelessness Scale $(r=-0.50, P=0.003)$; thus, higher post-prednisolone cortisol was associated with lower level of hopelessness. The correlations between $\mathrm{AUC}_{\mathrm{PRED}}$ and the other psychometric measures were not significant in patients. Mirroring the post-prednisolone data, there was a significant negative

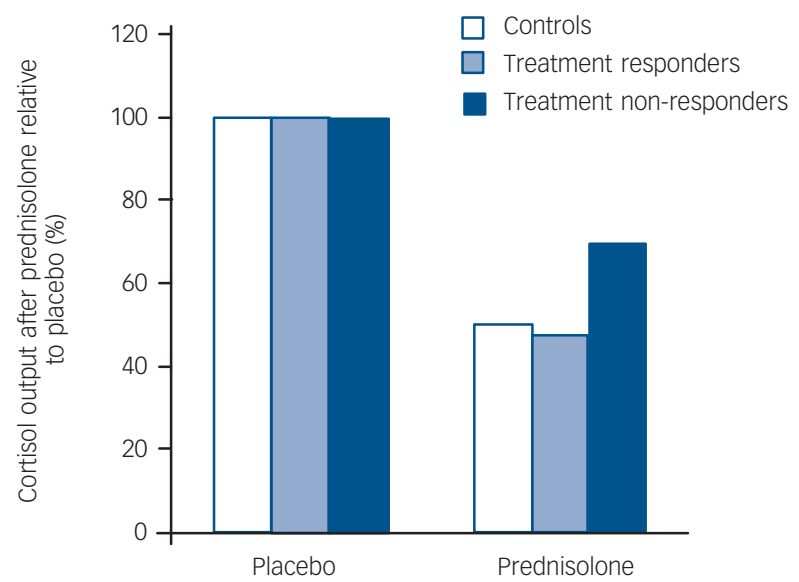

Fig. 4 Cortisol output (measured as area under the curve) after $5 \mathrm{mg}$ prednisolone relative to placebo (rebased to $100 \%)$ in 46 healthy controls and 45 patients. Patients who subsequently responded to treatment $(n=24)$ showed the same sensitivity to the suppressive effects of prednisolone as controls $(P=0.66)$, whereas treatment non-responders $(n=21)$ showed lesser sensitivity $(P=0.02)$ 
correlation between the AUC PLACEBO $_{\text {and the Beck Hopelessness }}$ Scale $(r=-0.46, P=0.006)$. There was no significant correlation between the percentage suppression of $\mathrm{AUC}_{\mathrm{PRED}}$ and any of the psychometric measures using the adjusted significance threshold of $P<0.027$. There was no difference in $A U C_{\text {PLACEBO }}$ and $\mathrm{AUC}_{\mathrm{PRED}}$ between patients with and without any comorbid personality disorder, or with and without individual personality disorder diagnoses. Similarly, there was no difference in $\mathrm{AUC}_{\mathrm{PLACEBO}}$ and $\mathrm{AUC}_{\mathrm{PRED}}$ between patients with and without early life stress, either taken as a whole or separated into emotional, physical or sexual abuse. Finally, the presence of a comorbid Axis I anxiety disorder did not affect significantly the AUC ${ }_{\text {PLACEBO }}$ or the AUC $C_{\text {PRED }}$.

\section{Plasma prednisolone levels}

Plasma prednisolone levels during the PST did not differ between patients and controls $(t=-0.86, P=0.40)$ or between treatment responders and non-responders $(t=-1.00, P=0.34$; Table 3$)$.

\section{Discussion}

We have, for the first time, assessed the relationship of endogenous HPA activity to prospectively defined severe treatment resistance in a cohort of in-patients with depression. We also used a novel test of HPA activity - the prednisolone suppression test - which allowed us to test the feedback function of both glucocorticoid and mineralocorticoid receptors on the HPA axis, and related the response to the clinical status of our patients.

\section{The HPA axis in in-patients with depression}

In this study, in-patients with severe depression and a moderate degree of retrospectively defined treatment resistance had higher salivary cortisol levels compared with controls, both after placebo and after prednisolone administration. This confirms previous findings reporting that people with severe depression have a hyperactive HPA, leading to high cortisol levels. ${ }^{8,31}$ Despite the marked basal hypercortisolism in these patients, the mean suppressive effect of prednisolone was similar to that seen in the healthy controls. This confirms our earlier data ${ }^{9}$ and focuses attention on why these patients show reduced suppression to the pure glucocorticoid receptor agonist dexamethasone but not to the mixed glucocorticoid receptor and mineralocorticoid receptor agonist prednisolone. ${ }^{9}$

Previous studies in depression with the dexamethasone suppression test and the dexamethasone-suppressed corticotrophin releasing hormone (Dex-CRH) test suggest impaired glucocorticoid receptor function, ${ }^{5,32}$ whereas other studies suggest that mineralocorticoid receptor function is upregulated. ${ }^{33}$ Both mineralocorticoid and glucocorticoid receptors are active in the negative feedback of the HPA axis. Since prednisolone is active at both receptor sites, our results taken together with these previous studies are compatible with the notion that in severe, treatment-resistant depression there is a change in differential responsiveness of the HPA axis to glucocorticoid and mineralocorticoid receptors, with increased mineralocorticoid receptor signalling compensating for impaired glucocorticoid receptor function. We conclude that in severe depression, rather than generalised glucocorticoid resistance there is an imbalance in the normal physiology of the regulation of the HPA axis characterised by glucocorticoid receptor resistance and increased mineralocorticoid receptor sensitivity. This is seen within a general resetting of HPA activity with markedly raised basal cortisol levels, suggesting a new set-point for HPA function but with intact negative feedback when this is measured using a more 'physiological' challenge able to activate both glucocorticoid and mineralocorticoid receptors. ${ }^{34}$

As expected for a group of patients with severe depression, there was a wide range of Axis I comorbidity, mainly anxiety disorders. Substantial data suggest that patients with depression comorbid with anxiety diagnoses have more severe depressive symptoms, a worse clinical course, a higher risk of suicide and possibly a different family history. ${ }^{35}$ However, the influence of comorbid anxiety disorders on the neuroendocrine picture of major depression has not been well studied. Although Young et al noted that patients with depression and comorbid anxiety disorders show even greater impairment to the negative feedback on the HPA axis than those without such comorbidity, ${ }^{36}$ this was not observable in our study.

\section{Relation to treatment response}

A particularly interesting aspect of our findings was that although as a whole this group of patients with depression showed preserved negative feedback, this did not apply to all patients. After completing the PST, patients underwent a period of intensive in-patient therapy. After this treatment, just over half the participants (53\%) were classified as treatment responders, with a concomitant improvement in several clinical measures. Those classed as non-responders had been prospectively treated with an intensive, evidence-based treatment package and thus represent a well-defined and truly treatment-resistant population (rather than an insufficiently treated population). We found that there was a significant difference in the AUC $\mathrm{CRED}_{\mathrm{PRE}}$ between these severely treatment-resistant patients and those who did eventually respond to treatment, in that a higher $\mathrm{AUC}_{\mathrm{PRED}}$ was associated with absence of clinical response to subsequent treatment. In other words, there was a higher post-prednisolone cortisol release (representing impaired suppression) in the severely treatmentresistant group compared with the treatment-responsive group. In contrast, no such relationship with clinical response was found

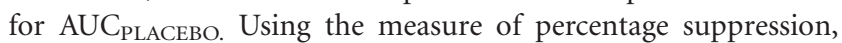
again there was significantly impaired suppression in the severely treatment-resistant group compared with the treatment responder group. The implication of this is that there may be a subgroup of patients within those who are severely depressed who have significant neuroendocrine dysfunction, represented by a disturbed HPA axis feedback and an imbalance in the ratio of mineralocorticoid/glucocorticoid receptor signalling, who are less responsive to the treatments currently available for depression and offered in an in-patient affective disorders unit. It may be that the underlying difference in these patients is an inability to compensate for glucocorticoid receptor resistance by increased mineralocorticoid receptor function. This would suggest that other treatment options need to be sought for such patients, and it could be that targeting the HPA axis is a fruitful area for future study in these patients.

Although this is the first study to use the PST to predict treatment response or resistance in depression, other HPA axis tests have been studied as predictors of treatment response. Baseline dexamethasone suppression test status did not predict response to antidepressant treatment or outcome after hospital discharge. ${ }^{5}$ Zobel et al found that patients who showed an increase in cortisol levels after the Dex-CRH test between admission and discharge tended to relapse during the follow-up period. ${ }^{6}$ Similarly, attenuation of the adrenocorticotrophic hormone response to the Dex-CRH test early during in-patient admission 
was linked with a positive treatment response after 5 weeks and a higher remission rate at the end of hospitalisation. ${ }^{37}$

The potential advantages of the PST are that it is simple to administer and tests both glucocorticoid and mineralocorticoid receptors rather than just glucocorticoid receptor alone, an important factor given our improved understanding of the HPA axis in recent years. Furthermore, we are not aware of data from other tests of the HPA axis that have been applied specifically to patients with severe depression with retrospectively defined treatment resistance. Given the expense of in-patient treatment programmes and the scarcity of available expertise, any advance in predicting which patients are most likely to benefit from these programmes could be important clinically.

\section{Relation to psychometric measures}

We found a higher level of hopelessness to be associated with both a lower $\mathrm{AUC}_{\mathrm{PRED}}$ and a lower AUC $\mathrm{ALACEBO}_{\text {. The hopelessness }}$ theory of depression is a cognitive vulnerability-stress model that attempts to understand risk factors for suicide behaviour. ${ }^{38}$ In this model certain vulnerable patients experience increased symptoms of hopelessness and depression when they experience negative life events. ${ }^{39}$ Two studies have used this model to investigate the link between the HPA axis and hopelessness; both showed that lower HPA axis activation - assessed either by free cortisol levels or with dexamethasone suppression - is associated with greater hopelessness, consistent with our finding. ${ }^{40,41}$ The interpretation of this finding might be that there is maladaptive, enhanced negative feedback regulation of cortisol in patients at risk of suicide. If overactive negative feedback were a risk factor for becoming hopeless in the face of life events, it would be important to investigate whether this is a trait variable that persists in patients, even when recovered.

\section{Early life stress}

Around $70 \%$ of our sample of patients had early life stress according to the items of the CECA-Q. However, there was no significant difference between $\mathrm{AUC}_{\mathrm{PRED}}$ and $\mathrm{AUC} \mathrm{C}_{\mathrm{PLACEBO}}$ in patients with or without early life stress, perhaps due to the high rate in this sample. Others have reviewed the literature in this area and concluded that early life stress may lead to disruptions in HPA axis functioning, and that factors such as the age when maltreatment occurred, parental responsiveness, subsequent exposure to stressors, type of maltreatment and type of psychopathology or behavioural disturbance displayed may influence the degree and pattern of HPA disturbance. ${ }^{42,43}$

\section{Limitations}

This study has some limitations. First, our sample size was modest, although this is the largest study of the PST to date and is comparable in size to previous studies using other HPA axis tests such as the Dex-CRH test to predict outcome. ${ }^{6,37}$ Second, all participants in the depression group were in-patients who were chronically ill with moderate prior treatment resistance. The sensitivity of the prednisolone test might be different in an outpatient group, as reported for other tests of HPA axis function. ${ }^{44,45}$ Third, the use of medication might have affected results. One mechanism for this might be through pharmacokinetic interactions altering the metabolism of prednisolone, as has been demonstrated for dexamethasone in some studies. However, we demonstrated that the prednisolone plasma levels were similar not only between patients and controls but also, importantly, between responders and non-responders, excluding such an effect. Another mechanism could be the direct effect of medication on the HPA axis. Although this is possible, Kunugi et al demonstrated that hormonal measures did not differ between patients receiving medication and patients without medication on admission, indicating that medication status did not affect Dex-CRH test results. ${ }^{46}$ This observation is in line with the finding that the presence or absence of antidepressant treatment and the type and number of antidepressant treatments during the index episode had no effect on hormonal responses to the Dex-CRH test. ${ }^{47}$

\section{Clinical implications}

This study confirms that there is HPA axis overactivity in in-patients with severe depression, characterised by raised basal cortisol levels. Although we find an intact negative feedback system reset to this higher level, our results taken together with prior studies suggest that this intact feedback depends on enhanced mineralocorticoid receptor sensitivity compensating for glucocorticoid receptor resistance. However, in prospectively defined severely treatment-resistant patients who do not respond to an intensive evidence-based treatment package, this compensatory mechanism is not functional and these patients demonstrate a combination of high cortisol levels and impaired negative feedback. It is, therefore, the patients who show the greatest neuroendocrine dysfunction on admission (i.e. non-suppression to prednisolone) who prove to be the least responsive to treatment.

The categorisation of depressive illnesses continues to develop and many have suggested that at some stage the addition of reliable biomarkers would advance this process. This study adds to evidence that HPA axis changes have an important role in depression and, we suggest, in the aetiology of treatment resistance in depression. However, we should learn from the mistakes of the past, when the dexamethasone suppression test was pursued as a 'diagnostic test' for depression or used as a proxy for an 'endogenous' subtype of depressive illness; any model would best incorporate markers of neuroendocrine dysfunction such as the PST alongside psychopathological and other indicators of treatment response and prognosis. Such improvements in the categorisation of depression to incorporate biomarkers should eventually open new therapeutic avenues and ultimately improve the outcome for patients with this often incapacitating and persistent illness.

\section{Mario F. Juruena, MD, MPhil, MSC, PhD, Section of Neurobiology of Mood Disorders, and Stress, Psychiatry and Immunology Laboratory (SPI-Lab), Institute of Psychiatry, London, and National Affective Disorders Unit, Bethlem Royal Hospital, Beckenham; Carmine M. Pariante, MD, MRCPsych, PhD, SPI-Lab, Institute of Psychiatry, London; Andrew S. Papadopoulos, PhD, MSC, CChem, MRGC, Csci, Lucia Poon, RGN, SCM, RMN, National Affective Disorders Unit, Bethlem Royal Hospital, Beckenham; Stafford Lightman, PhD, FRCP, FMedSci, Henry Wellcome Laboratories for Integrative Neuroscience and Endocrinology University of Bristol; Anthony J. Cleare BSC, MBBS, MRCPsych, PhD, section of Neurobiology of Mood Disorders, Institute of Psychiatry, London, and National Affective Disorders Unit, Bethlem Royal Hospital, Beckenham, UK}

Correspondence: Dr Anthony J. Cleare, Section of Neurobiology of Mood Disorders, PO 74, Institute of Psychiatry, 103 Denmark Hill, London SE5 8AF, UK. Email: a.cleare@iop.kcl.ac.uk

First received 21 Jan 2008, final revision 1 Oct 2008, accepted 10 oct 2008

\section{Funding}

The study was supported by Fundacao Coordenacao de Aperfeicoamento de Pessoal de Nivel Superior (CAPES), the National Alliance for Research on Schizophrenia and Depression (NARSAD), the Medical Research Council (MRC) and the National Institute for Health Research (NIHR) Biomedical Research Centre at South London and Maudsley NHS Trust and Institute of Psychiatry (King's College London). This research has been supported by a 2003 and 2005 NARSAD Young Investigator Award and a 2004 MRC Clinician Scientist Fellowship to C.M.P.; by a 2003 CAPES Fellowship Award and a 2006 NARSAD Young 
Investigator Award to M.F.J.; and by the NIHR Biomedical Research Centre at South London and Maudsley NHS Trust and Institute of Psychiatry (King's College London).

\section{Acknowledgements}

The authors are particularly grateful to $\operatorname{Dr}$ A. Verma and $\mathrm{Dr}$ S. Wooderson for their contribution to the data collection.

\section{References}

1 Olsen LR, Mortensen EL, Bech P. Prevalence of major depression and stress indicators in the Danish general population. Acta Psychiatr Scand 2004; 109: 96-103.

2 Juruena MF, Cleare AJ, Pariante $\mathrm{CM}$. The hypothalamic pituitary adrenal axis, glucocorticoid receptor function and relevance to depression. Rev Bras Psiquiatr 2004; 26: 189-201.

3 Bauer ME, Papadopoulos A, Poon L, Perks P, Lightman SL, Checkley S, et al. Dexamethasone-induced effects on lymphocyte distribution and expression of adhesion molecules in treatment-resistant depression. Psychiatry Res 2002; 113: 1-15.

4 Bauer ME, Papadopoulos A, Poon L, Perks P, Lightman SL, Checkley S, et al. Altered glucocorticoid immunoregulation in treatment resistant depression. Psychoneuroendocrinology 2003; 28: 49-65.

5 Ribeiro SC, Tandon R, Grunhaus L, Greden JF. The DST as a predictor of outcome in depression: a meta-analysis. Am J Psychiatry 1993: 150 1618-29.

6 Zobel AW, Yassouridis A, Frieboes RM, Holsboer F. Prediction of mediumterm outcome by cortisol response to the combined dexamethasone-CRH test in patients with remitted depression. Am J Psychiatry 1999; 156: 949-51.

7 Pariante CM, Papadopoulos AS, Poon L, Checkley SA, English J, Kerwin RW et al. A novel prednisolone suppression test for the hypothalamic-pituitaryadrenal axis. Biol Psychiatry 2002; 51: 922-30.

8 De Kloet ER, Vreugdenhil E, Oitzl MS, Joels M. Brain corticosteroid recepto balance in health and disease. Endocr Rev 1998; 19: 269-301.

9 Juruena MF, Cleare AJ, Papadopoulos AS, Poon L, Lightman S, Pariante CM. Different responses to dexamethasone and prednisolone in the same depressed patients. Psychopharmacol 2006; 189: 225-35.

10 American Psychiatric Association. Diagnostic and Statistical Manual of Mental Disorders (4th edn) (DSM-IV). APA, 1994.

11 Beck AT, Steer RA, Ball R, Ranieri W. Comparison of Beck Depression Inventories -IA and -II in psychiatric outpatients. J Pers Assess 1996; 67 588-97.

12 Hamilton M. A rating scale for depression. J Neuro Neurosurg Psychiatry 1960; 23: 56-62.

13 First MB, Spitzer RL, Gibbon M, Williams JBW. Structured Clinical Interview for DSM-IV Axis I Disorders - Clinician Version (SCID-CV). American Psychiatric Press, 1997

14 First MB, Spitzer RL, Gibbon M, Williams JBW. The Structured Clinical Interview for DSM-III-R Personality Disorders (SCID-II) .1. Description. J Personal Disord 1995; 9: 83-91.

15 Sackeim HA, Prudic J, Devanand DP, Decina P, Kerr B, Malitz S. The impact of medication resistance and continuation pharmacotherapy on relapse following response to electroconvulsive therapy in major depression. $J$ Clin Psychopharmacol 1990; 10: 96-104.

16 Thase ME, Rush AJ. When at first you don't succeed: sequential strategies for antidepressant nonresponders. J Clin Psychiatry 1997; 58 (suppl 13): 23-9.

17 Montgomery SA, Åsberg M. A new depression scale designed to be sensitive to change. Br J Psychiatry 1979; 134: 382-9.

18 Rush AJ, Gullion CM, Basco MR, Jarrett RB, Trivedi MH. The Inventory of Depressive Symptomatology (IDS). Psychometric properties. Psychol Med 1996; 26: 477-86.

19 Beck AT, Epstein N, Brown G, Steer RA. An inventory for measuring clinical anxiety: psychometric properties. J Consult Clin Psychol 1988; 56: 893-7.

20 Beck AT, Steer RA, Ranieri WF. Scale for Suicide Ideation: psychometric properties of a self-report version. J Clin Psychol 1988; 44: 499-505.

21 Beck AT, Weissman A, Lester D, Trexler L. The measurement of pessimism: the hopelessness scale. J Consult Clin Psychol 1974; 42: 861-5.

22 Folstein MF, Folstein SE, McHugh PR. 'Mini-mental state'. A practical method for grading the cognitive state of patients for the clinician. JPsychiatric Res 1975; 12: 189-98.

23 Bosc M, Dubini A, Polin V. Development and validation of a social functioning scale, the Social Adaptation Self-evaluation Scale. Eur Neuropsychopharmacol 1997; 7 (suppl 1): S57-70.
24 Rust J, Bennun I, Crowe M, Golombok S. The construction and validation of the Golombok Rust Inventory of Marital State. Sex Marital Ther 1986; 1 $34-40$.

25 Weissman AN. The dysfunctional attitude scale. A validation study. Diss Abst Int 1979; 40: 1389-90B.

26 Buysse DJ, Reynolds CF, Monk TH, Berman SR, Kupfer DJ. The Pittsburgh Sleep Quality Index: a new instrument for psychiatric practice and research. Psychiatry Res 1989; 28: 193-213.

27 Rahe RH. Life change events and mental illness: an overview. J Human Stress 1979; 5: 2-10.

28 Bifulco A, Brown GW, Harris TO. Childhood Experience of Care and Abuse (CECA): a retrospective interview measure. J Child Psychol Psychiatry 1994; 35: 1419-35.

29 Bifulco A, Bernazzani O, Moran PM, Jacobs C. The childhood experience of care and abuse questionnaire (CECA.Q): validation in a community series. $\mathrm{Br}$ J Clin Psychol 2005; 44: 563-81.

30 Taylor D, Paton C, Kerwin R (eds). The South London and Maudsley NHS Trust Oxleas NHS Trust Prescribing Guidelines (8th edn). Taylor \& Francis, 2005.

31 Gold PW, Chrousos GP. Organization of the stress system and its dysregulation in melancholic and atypical depression: high vs. Iow $\mathrm{CRH} / \mathrm{NE}$ states. Mol Psychiatry 2002; 7: 254-75.

32 Holsboer F. The corticosteroid receptor hypothesis of depression. Neuropsychopharmacology 2000; 23: 477-501.

33 Young EA, Lopez JF, Murphy-Weinberg V, Watson SJ, Akil H. Mineralocorticoid receptor function in major depression. Arch Gen Psychiatry 2003; 60: 24-8.

34 Juruena MF. The neurobiology of treatment resistant depression: role of the hypothalmic-pituitary-adrenal axis and glucocorticoid and mineralocorticoid receptor function. PhD thesis, University of London, Institute of Psychiatry, 2007.

35 Kara S, Yazici KM, Gulec C, Unsal I. Mixed anxiety-depressive disorder and major depressive disorder: comparison of the severity of illness and biological variables. Psychiatry Res 2000; 94: 59-66.

36 Young EA, Abelson JL, Cameron OG. Effect of comorbid anxiety disorders on the hypothalamic-pituitary-adrenal axis response to a social stressor in major depression. Biol Psychiatry 2004; 56: 113-20.

37 Ising M, Horstmann S, Kloiber S, Lucae S, Binder EB, Kern N, et al. Combined dexamethasone/corticotropin releasing hormone test predicts treatment response in major depression - a potential biomarker? Biol Psychiatry 2007; 62: 47-54.

38 Beck AT, Brown G, Berchick RJ, Stewart BL, Steer RA. Relationship between hopelessness and ultimate suicide: a replication with psychiatric outpatients. Am J Psychiatry 1990; 147: 190-5.

39 Whisman MA, Kwon P. Life stress and dysphoria: the role of self-esteem and hopelessness. J Pers Soc Psychol 1993; 65: 1054-60.

40 Engstrom G, Alling C, Gustavsson P, Oreland L, Traskman-Bendz L. Clinical characteristics and biological parameters in temperamental clusters of suicide attempters. J Affect Disord 1997; 44: 45-55.

41 Jacobs S, Bruce M, Kim K. Adrenal function predicts demoralization after losses. Psychosomatics 1997; 38: 529-34.

42 Heim C, Newport DJ, Wagner D, Wilcox MM, Miller AH, Nemeroff CB. The role of early adverse experience and adulthood stress in the prediction of neuroendocrine stress reactivity in women: a multiple regression analysis. Depress Anxiety 2002; 15: 117-25.

43 Nemeroff CB, Heim CM, Thase ME, Klein DN, Rush AJ, Schatzberg AF, et al. Differential responses to psychotherapy versus pharmacotherapy in patients with chronic forms of major depression and childhood trauma. Proc Natl Acad Sci USA 2003; 100: 14293-6.

44 Gervasoni N, Bertschy G, Osiek C, Perret G, Denis R, Golaz J, et al. Cortisol responses to combined dexamethasone/CRH test in outpatients with a major depressive episode. J Psychiatr Res 2004; 38: 553-7.

45 Watson S, Gallagher P, Del-Estal D, Hearn A, Ferrier IN, Young AH. Hypothalamic-pituitary-adrenal axis function in patients with chronic depression. Psychol Med 2002; 32: 1021-8.

46 Kunugi $\mathrm{H}$, Ida I, Owashi T, Kimura M, Inoue $\mathrm{Y}$, Nakagawa $\mathrm{S}$, et al. Assessment of the dexamethasone/CRH test as a state-dependent marker for hypothalamic-pituitary-adrenal (HPA) axis abnormalities in major depressive episode: a multicenter study. Neuropsychopharmacology 2006; 31: 212-20.

47 Kunzel HE, Binder EB, Nickel $T$, Ising $M$, Fuchs $B$, Majer $M$, et al. Pharmacological and nonpharmacological factors influencing hypothalamicpituitary-adrenocortical axis reactivity in acutely depressed psychiatric inpatients, measured by the Dex-CRH test. Neuropsychopharmacology 2003; 28: $2169-78$. 